\title{
Literalidad, ironía y ambigüedad calculada
}

\section{Literality, irony and calculated ambiguity}

\author{
JUAN A. MARTÍNEZ LÓPEZ \\ MARIANO REYES TEJEDOR ${ }^{\mathrm{a}}$ \\ ${ }^{a}$ Universidad Pablo de Olavide, Facultad de Humanidades. España. \\ Correos electrónicos: jamarlop@upo.es, mreytej@upo.es
}

\begin{abstract}
El presente estudio muestra que, en ciertas circunstancias y en frases de uso frecuente, los hablantes neutralizan intencionalmente la entonación de ciertas frases para crear ambigüedad. La estructura elegida para analizar el fenómeno mencionado es la expresión española ¡qué cabrón!', que, si bien usada en un sentido literal es fuertemente ofensiva, en sentido irónico adquiere un significado próximo al elogio. La grabación de conversaciones espontáneas entre jóvenes permite mostrar la existencia de diferentes categorías de entonación, en función del contexto lingüístico y extralingüístico en el que se pronuncian. El análisis de la información sugiere que la neutralización de la entonación estándar parece estar relacionada con la tensión producida en los individuos debido a un conflicto entre lo expresado y sus convicciones (disonancia), o entre lo expresado y las normas y valores que unen el grupo al que pertenece (incongruencia).
\end{abstract}

Palabras clave: entonación, ironía, polisemia, disonancia, incongruencia, sarcasmo.

This paper documents that in certain circumstances and in frequently used phrases, speakers intentionally neutralize the intonation of certain phrases in order to create ambiguity. The expression chosen to analyse the above-mentioned phenomenon is the Spanish expression iqué cabrón! [what a bastard!] which in a literal sense is strongly offensive, but when declared ironically, acquires a meaning close to praise. The recording of free conversations among young people presents different categories of intonations depending on the linguistic and extra linguistic context in which they are pronounced. The analysis of the information shows that the neutralization of the standard intonation seems to be related to the tension produced in the individual due to a conflict between the expressed and his or her convictions (dissonance), or between the expressed and the norms and values that bond the group he or she belongs to (incongruence).

Key words: intonation, polisemy, irony, dissonance, incongruence, sarcasm. 


\section{INTRODUCCIÓN}

La ironía o uso irónico del lenguaje se define como la capacidad de un enunciado de expresar lo contrario de lo que dice literalmente; por ello se ha señalado repetidamente que la ironía es la antífrasis por naturaleza. No obstante esta definición general, la frase irónica está siempre referida y articulada en torno a un contexto lingüístico y a una situación extralingüística determinada, que trasmiten las pautas desde las que debe abordarse la expresión para su procesamiento correcto, es decir, en el sentido deseado por el que profiere la expresión irónica. Desde esta perspectiva, y como recogen la generalidad de los trabajos que tocan este aspecto, la ironía es un acto de habla deliberado, pues se formula con la pretensión de que una frase irónica sea procesada y entendida como tal. Así, en aras de mantener una conversación eficaz los hablantes utilizan el mensaje irónico ciñéndose a las habilidades y características de los destinatarios del mensaje. Pese a lo señalado, hay varias cuestiones que han despertado el interés de los investigadores. Una de ellas es por qué no todos los hablantes de una lengua natural tienen una capacidad similar para captar el mensaje irónico (Kaufer 1977). Tal diferencia ha quedado explicada alegando una limitada capacidad cognitiva por parte de algunos interlocutores. En esta misma línea también se ha indicado que el procesamiento de una expresión irónica precisa del conocimiento del entorno y de las circunstancias en que se origina dicha expresión, así como de una serie de expectativas que conducen al interlocutor al sentido que el hablante desea trasladar (Katz y Pexman 1997; Colston y Lee 2004; Goddard 2006). Así pues, desde esta vertiente, la dificultad para procesar correctamente una ironía se debería a la falta de habilidad o aptitud del receptor, al ser incapaz de captar las señales emitidas por el hablante e indicativas de cómo procesar una frase. Por tanto, la imposibilidad por parte del interlocutor de captar las señales que envía el hablante, o la existencia de dificultades de cualquier otro tipo como, por ejemplo, desconocer el contexto cultural, social, etc., podrían crear una situación de ambigüedad no intencionada que llevaría a una interacción fallida.

A los "obstáculos" ya comentados para el efectivo procesamiento del mensaje irónico, hay que señalar otros aspectos que aumentan dicha dificultad, aunque esta vez desde la propia formulación de la ironía. En este sentido, hay estudios que describen el hecho de que no siempre el mensaje irónico es deliberado (Gibbs 2012). Dicha tesis defiende que, en determinados casos, el oyente no dispone de señales intencionales directoras para la interpretación del mensaje. Por otra parte, cabe considerar los casos en que el mensaje se formula con una entonación intencionalmente ambigua. De hecho, en este último caso se inscribe el presente estudio. El punto de partida viene motivado por la observación y percepción de que en espańol hay determinadas frases de gran frecuencia de uso entre los jóvenes, que se prestan a una variedad de entonaciones que va más allá de la duplicidad literal-irónica. Para profundizar en todo ello, hemos tomado como ejemplo prototípico la expresión iqué cabrón! y hemos utilizado la grabación de conversaciones reales no dirigidas de un grupo de jóvenes, los más proclives al uso de dicha expresión. El entorno en que se profiere la frase en cuestión, así como la entonación utilizada, nos aportan valiosa información 
para verificar y profundizar en lo que no era, en principio, más que una impresión personal. La percepción de una particular modulación, que va más allá de las dos entonaciones más habituales (literal-descendente o irónica-ascendente), nos da pie a indagar si no estamos ante una forma preconstituida de ambigüedad intencional, similar a la existente en otro tipo de fenómenos lingüísticos (Nerlich y Clarke 2001). Para profundizar en el análisis se tendrá en cuenta el contexto en que son expresadas, necesario para indagar si el enmascaramiento de una entonación está relacionado con las tensiones sufridas por el propio hablante al entrar en conflicto su comportamiento con sus valores o principios (Festinger 1957); o bien con aquellas reglas o valores que sustentan el grupo del que el hablante forma parte (Eckhardt y Hendershot 1967). Ello implicaría la necesidad de un acto de desambiguación por parte de los interlocutores del miembro grupal, que explotarían la congruencia que cohesiona el grupo como elemento para eliminar dicha ambigüedad.

\section{LA IRONÍA}

Recientes trabajos han puesto de relieve que tras el concepto de ironía se esconde una serie de situaciones y fenómenos lingüísticos de variada naturaleza, cuyo proceso de reconocimiento supone en ocasiones un reto para el oyente (Gibbs 2000; Shelley 2001; Gibbs y Colston 2007). Lucariello (1994) muestra que el rasgo más sobresaliente de la ironía es lo sorprendente, lo inesperado, y establece siete tipos básicos de situación irónica, cada uno a su vez con varios subtipos. Así, la ironía puede hallarse tanto en meras situaciones (eventos no lingüísticos) carentes de lenguaje verbal, como en aquellas en que el lenguaje ayuda a conformar la realidad global de un evento. Algunos autores han señalado que la ironía no supone un fenómeno único y bien delimitado, sino que bajo dicha rúbrica se engloban diferentes usos del lenguaje, que incluirían el sarcasmo, la jocularidad, la hipérbole, la pregunta retórica y la subestimación (Gibbs 2000). Con respecto al particular modo de entonación de las frases irónicas, algunos autores han señalado que, desde el punto de vista lingüístico, la ironía no se puede concebir como un procedimiento lingüístico con moldes fijos; es decir, no hay una estructura netamente irónica (Casas 2004). No obstante, ello no es óbice para que esté comúnmente admitido que, en la inmensa mayoría de las ocasiones, la emisión de la ironía conlleva una imitación melódica y tonal prototípica que podemos englobar en lo que Coseriu (2007[1980]: 205) denominó función icástica del signo. A este respecto, señala que

En el caso de la imitación indirecta por la articulación, dicho en términos de fonética actual, no se trata tanto de la impresión auditiva o de la imagen sonora como de la articulación, esto es, de los movimientos que hay que realizar para producir determinados sonidos o combinaciones de sonidos. Aquí de algún modo se establece una correspondencia entre la articulación y lo designado. (209) 
Así pues, la interpretación irónica de un enunciado dependerá, por tanto, de las claves relacionadas con múltiples rasgos. Tales rasgos pueden ser agrupados en dos tipos: indicadores y marcas (Attardo, Eisterhold, Hay y Poggi 2003; Kocman 2011). Los primeros muestran la incoherencia entre el mensaje proferido y la realidad a que se alude, es decir, el mensaje irónico siempre implica algún tipo de diferencia en la valencia que se evalúa (Partington 2007; Burgers, Van Mulken y Schellens 2011). Los segundos son las señales con las que el hablante acompaña el mensaje proferido a fin de que el oyente descodifique la expresión en el sentido idóneo. Dichas señales son de dos tipos: por un lado, una particular entonación. A este respecto, Dews y Winner (1997: 391) señalan que:

The type of intonation used was also related to the situation in which the irony was used. When speakers were annoyed, they used a negative, mocking intonation, when speakers were in a playful mood, or were trying to seem superior, they used either deadpan or mock-sincere intonation.

Por otro, se ha destacado la expresión facial como otra de las características que acompañan a la emisión de un enunciado irónico. Ambas señales enviadas por el emisor (entonación y expresión facial) parecen utilizarse de modo paralelo; es decir, una entonación negativa se asocia a una expresión facial negativa, mientras una entonación sincera (positiva) se asocia a una expresión facial positiva (Dews y Winner 1997). Así, el hecho de que la ironía verbal pueda manifestarse mediante muy variadas estructuras lingüísticas, el que haya que interpretarla en función del desajuste entre la realidad y lo proferido, y que la interpretación irónica esté condicionada a la comprensión de múltiple factores: entonación, contexto lingüístico, ámbito cultural, gestos y situaciones humorísticas preestablecidas (Kreutz 1996; Attardo 2000 a y b), ha tenido como resultado un fuerte debate en torno a la misma definición de ironía (Kerbrat-Oreccioni 1980; Clark y Gerrig 1984; Albaladejo 1990; Wilson y Sperber 1992; Giora 1995).

Teniendo en cuenta las características del mensaje irónico a las que hemos aludido, un primer acercamiento podría llevarnos a pensar que el interlocutor recibe suficientes señales como para saber cuándo está recibiendo un mensaje irónico y, en consecuencia, procesarlo como tal. Sin embargo, nada más lejos de la realidad. Ello no quiere decir que no haya casos en que resulta evidente que una expresión ha de ser interpretada en sentido irónico, como, por ejemplo, cuando es obvia la existencia de una contradicción evidente ( $E l$ guepardo es, por naturaleza, lento como un rayo), más allá de las marcas ilocutivas con que sea pronunciada. Así, como indica Gibbs (2012: 106):

These situations sometimes feel ironic and evoke strong emotional reactions precisely because people recognize the significant incompatibility between what they personally desired and what has occurred, enough so that the sense of irony pops into consciousness. 
Sin embargo, las posibilidades del discurso irónico son tan amplias y están sujetas a tan diferentes factores, que no es especialmente extraño que un enunciado irónico sea malinterpretado por determinados individuos. Téngase en cuenta que la ironía también existe en los textos escritos, así como en determinados actos en el entorno de la comunicación no verbal. Tomando como referencia lo que acabamos de señalar, algunos estudios han mostrado que no todos los individuos son capaces de usar y procesar la ironía de modo similar, sino que ello depende de las características de cada persona, incluso del género (Colston y Lee 2004), de la actividad profesional y el entorno ocupacional del hablante (Katz y Pexman 1997), de factores derivados del entorno cultural del país (Goddard 2006) o, incluso, de la región de procedencia (Dress, Kreuz, Link y Caucci 2008).

Así pues, la interpretación correcta de la ironía exige una labor de descodificación basada en conocimientos culturales, recuerdos, vivencias, situaciones, etc., que no están al alcance de todos. Por ello, la ironía verbal no suele suponer un fracaso comunicativo cuando la comunicación se realiza entre individuos que mantienen cierta familiaridad, pues en tales circunstancias el hablante conoce las claves que ha de tener el mensaje irónico para ser comprendido correctamente por el interlocutor. En este sentido, la ironía está muy próxima al humor, ya que una descodificación incorrecta da al traste con la interpretación humorística. No es por tanto la ironía una mera incongruencia entre los términos del acto de habla irónico, pues de ser así la competencia gramatical sería más que suficiente para interpretar correctamente un enunciado de esa naturaleza (Curcó 1998; Kocman 2011; Machado 2014). Prueba de ello es que los niños de corta edad, de cinco o seis años, suelen tener una competencia gramatical plena, pero son por lo general incapaces de comprender ironías o metáforas de cierta complejidad. No obstante, la dificultad para interpretar correctamente la ironía verbal no solo afecta a niños de corta edad, sino que la percepción y comprensión de esta establece dos tipos de individuos (Kaufer 1977). De hecho, algunos trabajos muestran la existencia de un grupo de personas con gran facilidad para comprender el lenguaje irónico (wolves), a la vez que otros se enfrentan con grandes dificultades para la idónea comprensión de la ironía (sheep) (Gibbs e Izett 2005). Otra de las diferencias entre los receptores de un mensaje irónico es la establecida en torno al acuerdo o desacuerdo que estos manifiestan respecto del significado intencional de dicho mensaje. Así, aquellos receptores del mensaje irónico que están de acuerdo con el contenido de este se denominan confederates; los que están en desacuerdo con dicho mensaje son victims (Gibbs 2012). Este déficit en la comprensión de las secuencias irónicas de algunos individuos puede reflejar limitaciones en la habilidad para entender señales como las intenciones, las creencias o las emociones (Shamay-Tsoory, Tormer y Aharon-Peretz 2005).

\subsection{Polisemia y ambigüedad (calculada) en el mensaje irónico}

La polisemia ha sido vista tradicionalmente como un fenómeno semántico mediante el que una misma palabra o frase era portadora de varios significados. Aún hoy la polisemia supone un importante reto para la lingüística cognitiva y para la computacional, entre 
otras disciplinas (Nerlich y Clarke 2001). Estos diferentes significados vienen derivados de los diferentes contextos en que una palabra o frase puede ser utilizada. En este contexto, algunas investigaciones han puesto de relieve que, pese a que ciertas palabras de modo aislado poseen más de un significado, el contexto desempeña un papel fundamental para discriminar el sentido deseado por el hablante. Se trata, por tanto, de una selección por parte del interlocutor, de entre las posibles interpretaciones, coherente con el contexto en que se desarrolla el acto comunicativo (Kittay 1987).

En principio, el deseo de una comunicación unívoca rehúye el uso de aquellas palabras o expresiones polisémicas en aras de evitar los malentendidos derivados de la ambigüedad, por lo que se puede decir que los hablantes, por lo general, respetan el denominado principio de convencionalidad, según el cual, a cada forma lingüística corresponde un único significado (Lehrer 1990; Clark 1993). Pese a todo, algunos autores consideran que "la ambigüedad es, sin lugar a dudas, uno de los universales más patentes del lenguaje natural, y esta propiedad, que constituye un molesto inconveniente para ciertas clases de Sprachspiele, ha sido el motivo mayor que ha llevado a la invención de lenguajes más precisos por unívocos" (Michelena 1972: 237). Este autor distingue varios tipos de ambigüedad, entre ellas destaca la que denomina sintáctica, por ser "característica de aquellas construcciones que son como un resumen o abreviación de otras más explícitas [...]” (238).

No obstante, desde el trabajo publicado por Grice (1975) sabemos que la interacción conversacional presenta una enorme complejidad, dado el gran entramado de factores que inciden en ella: contexto lingüístico, contexto situacional, implicaturas, suposiciones, etc., y que en la práctica determinan que el significado de la palabra o frase aislada pueda ser diferente del significado que quiere transmitir el hablante. Así, el principio de cooperación describe y explica la lógica de los intercambios comunicativos por parte de los hablantes, aunque sea de forma inconsciente. Dicho principio va acompañado de unas máximas cuyo objetivo es que se produzca una conversación eficaz (con plena comunicación) y no un simple intercambio de premisas absurdas e inconexas. A pesar de ello, la observación de la realidad diaria nos muestra que en ocasiones no se respeta el principio de cooperación, al incumplir alguna de las máximas. Los desajustes entre lo dicho y lo interpretado por el oyente, Grice los solventa tomando como base las implicaturas. Tales implicaturas tienen como objeto complementar lo que se dice para que aparezca lo que se comunica. En este sentido cabe decir, en consecuencia, que el incumplimiento de una máxima no implica necesariamente que se incumpla el principio de cooperación que regula la conversación, pues con la ayuda de las implicaturas el interlocutor debe reinterpretar lo dicho y así, salvaguardar lo que se desea comunicar y, consecuentemente, el principio de cooperación. Pese a todo, Grice (1975) considera fenómenos como la ironía o la ambigüedad una violación de las normas que regulan la comunicación. Ahora bien, dados los anteriores desajustes (violación de las máximas), que en la práctica no impiden la interacción, llega a la conclusión de que este principio describe algunas de las reglas en que se basa la comunicación, pero no todas, pues, ciertamente, la finalidad de muchos intercambios comunicativos es intercambiar información veraz, precisa, de la manera más efectiva posible y sin ambigüedad. Sin 
embargo, dicho propósito es solo uno de las variadas finalidades con las que usamos el lenguaje en la vida diaria. De hecho, frecuentemente mantenemos conversaciones en las que no queremos dar una información precisa. Es más, el lenguaje se puede utilizar de forma meramente instrumental a fin de obtener una ventaja o beneficio más allá del contenido de la conversación. Pongamos como ejemplo el trabajador que se deshace en halagos hacia su jefe al objeto de que lo promocione dentro de la empresa. A tales comportamientos lingüísticos habría que añadir, por ejemplo, el uso de la metáfora, la ironía e, incluso, el lenguaje joculatorio, donde lo que prima son los dobles sentidos en busca de la distracción o la diversión utilizando el lenguaje como herramienta (Roberts y Kreuz 1994; Dews, Kaplan y Winner 1995).

Desde las teorías relevantistas, la ambigüedad derivada de la multiplicidad de significados, sobre todo en formulaciones como la ironía o la metáfora, es una cuestión semántica que atańe solo a las palabras o frases tomadas aisladamente, pues la ambigüedad de un término o expresión desaparece automáticamente al ser proferido en un acto comunicativo concreto, en virtud del entorno cognitivo (Mey 1993). Sin embargo, dicha teoría, centrada en el entorno cognitivo en que se sitúa el intercambio comunicativo, dice poco sobre cómo se produce la comunicación real (Giora 1997). Siguiendo esta línea, Nerlich y Clarke (2001: 4) señalan lo siguiente:

And yet, it is here that one can observe how much people love juggling with ambiguities. They are less concerned with communicative efficiency and much more with the pragmatic 'effects' they want achieve. In fact, we seem to have evolved an amazing ability to slide effortlessly up and down a scale of semantic options from being precise and monosemous in some circumstances to being vague and polysemous in others, depending on the conversational style and the situation of discourse.

Desde las dos teorías referidas, se da a entender que la comunicación dispone de una serie de herramientas de muy diversa naturaleza, cuya función es eliminar la posible ambigüedad derivada de la polisemia de palabras y frases. Pese a ello, no es extraño en el lenguaje real diario observar casos en que el hablante, de modo intencional, utiliza palabras, frases, e incluso mensajes completos que, precisamente en el contexto en que se articulan, presentan más de un significado. Esta denominada purposive ambiguity (Kittay 1987) aparece muy especialmente bajo la forma de metáfora, ironía o mensajes con intencional doble sentido. Pero, además, desde la perspectiva del receptor puede aparecer otro tipo de ambigüedad, ahora involuntaria y de carácter individual, debido a que este puede asignar al mensaje un sentido que va más allá del significado que el hablante atribuye a su propio mensaje.

Por lo general, la multiplicidad de significados de un enunciado ha sido considerado por los pragmáticos como un fenómeno meramente semántico. En este sentido puede hablarse de significados intencionados y no intencionados, relevantes e irrelevantes, donde la ambigüedad es descartada por irrelevante (Bach 1998). Sin embargo, como expondremos 
más adelante al comentar los resultados de nuestro análisis, coincidimos con Nerlich y Clarke (2001: 7) cuando, posicionándose en contra de lo expuesto, señalan que "the intentional use or the intentional abuse of irrelevant sense has specific pragmatic functions in linguistic interaction". De hecho, si bien es cierto que en la mayoría de las ocasiones el hablante profiere un mensaje cuyo contenido es congruente o consonante con el significado de la expresión (Dews y Winner 1997), no faltan casos en los que se observa incongruencia o disonancia:

[...] this has long been known about such classic indirect speech acts as 'Can you pass me the salt?', in which case, over time, (incongruent) form and communicational function have become congruent and the initial incongruence in no longer felt (Nerlich y Clarke 2001: 7).

La disonancia producida en los enunciados irónicos hace que tengamos que mantener presentes tanto el significado de la expresión como el significado que le otorga el hablante para entender la intención de este en un determinado contexto. Así, tal y como comenta Dews y Winner (1997), la frase irónica comentada sobre un taxista que conduce de modo deficiente: 'I love drivers who signal', dice lo que dice la frase, pero el significado que le otorga el hablante va más allá, puesto que simultáneamente está rechazando a los conductores que no señalizan. En este sentido, la frase irónica porta dos significados opuestos, tal y como indican Dews y Winner (1997: 379):

In sum, in literal language, the literal meaning is accepted, and the listener makes further inferences, ones that are consonant with the literal meaning. In nonliteral language, the literal meaning is rejected and the listener makes further inferences, ones that are dissonant with the rejected meaning.

Pese a todo, es conveniente recordar que el mensaje creado intencionalmente ambiguo también forma parte de la comunicación humana. Dicha ambigüedad puede estar motivada al menos por dos causas. La primera está basada en lo que R. Jakobson denominó "función poética del lenguaje". Ello significa que el lenguaje puede ser interpretado de diferentes modos, lo que atañe directamente a fenómenos como la ironía, la metáfora y mensajes con varias lecturas (como los chistes o los juegos de palabras). Y dicha ambigüedad no es inocente, sino que se hace con un determinado propósito:

In rhetorical modes such as advertising and political slogans, ambiguity is exploited for its attention-drawing quality. [...] An utterance in which a single meaning cannot be specified $[. .$.$] draws attention to itself and thereby captures our attention$ (Kittay 1987: 80).

La segunda causa de ambigüedad calculada a la que nos vamos a referir se circunscribe en la necesidad o deseo del hablante de ocultar a su interlocutor parte de la verdad. En 
principio podría pensarse que dicho comportamiento viola la máxima de calidad, según la cual la información trasmitida ha de ser verdadera. Sin embargo, el hecho de ocultar parte de dicha información no tiene por qué violentar las dos premisas de la citada máxima: no dar información que sea falsa, o no dar información que no se apoye en la evidencia. El hecho de ocultar al interlocutor parte de la información, no significa que no se aporte, también, información veraz, en la medida en que se apoya en evidencias o pruebas. Por otra parte, a nuestro juicio, la citada ocultación de parte de la información tampoco viola la máxima de cantidad (intenta dar la mayor información posible que puedas; da tanta información como sea necesaria y no más), en la medida en que lo que se oculta es una información subjetiva que no puede darse por la disonancia personal que implica, y porque, además, puede considerarse innecesaria al no impedir ni perjudicar el intercambio comunicativo.

\subsection{Planteamiento del problema}

Como hemos venido comentando, el mensaje irónico puede resultar ambiguo sin que medie voluntad por parte del hablante. A ello contribuyen varios factores. En primer lugar, el enunciado irónico se profiere acompańado de señales (entonación, gestos faciales o corporales), etc., que dan las claves para su interpretación correcta. Sin embargo, no siempre están presentes tales señales (enunciados escritos, conversaciones telefónicas, etc.), e incluso, cuando están presentes, la calidad o la claridad de estas, unidas con la sintonía o no del mensaje con las evidencias, hace que pueda aparecer la ambigüedad desde la perspectiva del oyente a la hora de procesar un enunciado irónico. Así, en un enunciado como el siguiente: - Mi hijo ha aprobado todos los exámenes con excelentes calificaciones. Es muy listo, el adjetivo 'listo' viene determinado por el contexto comunicativo y puede adoptar uno de los posibles significado: inteligente o astuto-hábil-zorro. En tal contexto, se intuye que el padre pretende asociar 'listo' al primero de los sentidos seńalados. Sin embargo, imaginemos el siguiente dialogo en que el padre del niño en cuestión habla con un vecino que conoce bien a la familia:

a) -Mi hijo ha aprobado todos los exámenes con excelentes calificaciones

b) -Sí, es muy listo (dicho por un vecino que conoce al niño en cuestión y sabe de su fama de habilidad para la marrullería y de su mediocre inteligencia)

En este segundo caso, la contestación por parte del vecino es congruente y disonante (Eckhardt y Hendershot 1967) si se parte de la información general que se tiene en la vecindad sobre el niño en cuestión. Lo seńalado por el vecino es deliberadamente ambiguo, pues no está seguro de si el niño ha trabajo mucho en esta ocasión para obtener las excelentes calificaciones o, por el contrario, son fruto de su manifiesta marrullería. En todo caso, la polisemia del término le permite "matar dos pájaros de un tiro".

La segunda causa a la que nos vamos a referir en relación con el enunciado irónico es la que denominamos 'ambigüedad intencional'. Tales expresiones fueron inicialmente fruto de la observación de determinadas estructuras breves de uso frecuente, particularmente 
entre personas con un cierto nivel de familiaridad. Lo observado es plenamente concordante con lo ya señalado por Nerlich y Clarke (2001: 15): "In actual conversations, purposive ambiguity is most common in interaction between friends and members of family and least common in legal and technical discourse".

Consecuentemente, la percepción de que existían determinadas estructuras que se prestaban a variadas entonaciones, y la intuición de que tales entonaciones eran realizadas voluntariamente además de tener un trasfondo semántico, nos llevó a estudiar con mayor profundidad dicho fenómeno. La estructura a la que nos estamos refiriendo está formada por la partícula "que" más una serie de adjetivos de uso bastante frecuente: iqué listo!, iqué hijoputa!, ¡qué cabrón! En estos casos, y en algún otro de valor ofensivo y disfemístico, tales expresiones han desarrollado dos valores bien conocidos. Por un lado, el constitutivo de ofensa en emisiones no irónicas; por otro, valores próximos al elogio o la admiración en proferimientos de carácter irónico. Tales estructuras y valores son usados más frecuentemente entre jóvenes con un cierto grado de familiaridad.

\section{Marco Metodológico}

Al objeto de ratificar o refutar nuestra primera impresión, hemos elegido la expresión ique cabrón! por ser, posiblemente, la de uso más frecuente, al menos en la franja de edad a la que pertenece el grupo de nuestros informantes. Así mismo, utilizaremos como material de análisis una serie de grabaciones de conversaciones coloquiales no dirigidas, cuyo objeto es analizar las entonaciones con que se articula la citada expresión en todos los casos en que sea recogida, así como estudiar los contextos lingüísticos y no lingüísticos en que han sido proferidas.

\subsection{Participantes}

Al objeto de llevar a cabo el estudio, se utilizó la grabación, como informantes, de un grupo de jóvenes de entre 17 y 19 años de ambos sexos. Todos de la provincia de Jaén y, por tanto, hablantes nativos de la zona dialectal de Andalucía oriental. Las grabaciones pertenecen al proyecto El habla juvenil de las capitales andaluzas. El grupo en cuestión varió en ocasiones a lo largo de los días en que tuvo lugar la grabación, pero siempre se mantuvo entre los seis y doce individuos. Es necesario señalar que al tratarse de un grupo de amigos existe un elevado grado de familiaridad entre ellos, por lo que las grabaciones son netamente coloquiales. A los menores de edad se les requirió el permiso de su padre o tutor para participar en el estudio.

\subsection{Procedimiento}

En una reunión se informó a todos los miembros del grupo de que se trataba de un trabajo científico y de que, por tanto, las grabaciones, así como las transcripciones de ese 
material, serían tratadas anónimamente y solo se utilizarían para dicho fin. Así mismo, se les indico que con las grabaciones se pretendía recoger su lenguaje más espontáneo, por lo que era necesario que actuaran tal y como lo hacían habitualmente, por lo que no debían inhibirse en el uso de tacos, expresiones propias de su edad, etc. Tras una corta observación del grupo para determinar quién/quiénes eran los más idóneos para portar la grabadora, se llegó a un acuerdo de los días y horas en que se llevaría a cabo la grabación. Las grabaciones fueron recogidas entre el 20 de junio y el 6 de julio de 2018. En total, 8 horas de grabación. A los dos portadores de las grabadoras se les instruyó de modo especial, tanto en el uso de la grabadora como en las condiciones idóneas de grabación.

\subsection{Extracto del material recogido}

La frase en cuestión, iqué cabrón!, apareció en veintisiete ocasiones a lo largo de las casi 8 horas de grabación. De estas, dieciséis casos fueron realizados con entonación claramente irónica; cuatro casos con entonación no irónica, y cinco casos de clara ambigüedad. Para comparar los escenarios en que se producen dichas diferencias hemos escogido un representante de cada tipo y transcribimos a continuación los contextos en que se producen.

1.- Entonación no irónica.

La situación en que se inscribe el dialogo que sigue es la siguiente: uno de los chicos que participan como informantes discute con una chica agriamente, sin haya una causa clara que justifique tal acritud. De modo inesperado, el chico vacía parte de su zumo sobre la ropa de la chica:

A: Esta vez es que te has pasado un huevo...

B: Pero, ¿qué ha pasado?

A: Nada, que aquí el artista no ha tenido más ocurrencia que ponerla perdida con su zumo.

B: ¿Pero, por qué?

C: Por una chorrada, pero todavía está que trina.

B: ¡Qué cabrón!

Como puede observarse en el gráfico más abajo, la expresión iqué cabrón! se profiere con una clara entonación exclamativa descendente. Tal y como señala Moreno (1994: 360-1), en español

[...] la entonación exclamativa se encuentra siempre o casi siempre en los enunciados con los que el hablante expresa determinadas actitudes: es el caso de tantos enunciados no verbales estereotipados -casi fórmulas fijas- para expresar asentimiento, aprobación, aplauso o rechazo, desdén, desacuerdo [...]. 
Ha de tenerse en cuenta que en sentido recto la palabra cabrón ya contiene un fuerte carácter ofensivo y recriminatorio hacia la persona a que se aplica. La exclamación descendente refuerza dicho contenido, particularmente cuando se acompaña de pronunciación más lenta y acento más fuerte. En el ejemplo que nos ocupa puede decirse que uno de los informantes ha realizado un acto intolerable, tanto para el que profiere la frase como para el resto del grupo.

Gráfico 1. Exclamación con tono descendente. Sentido literal

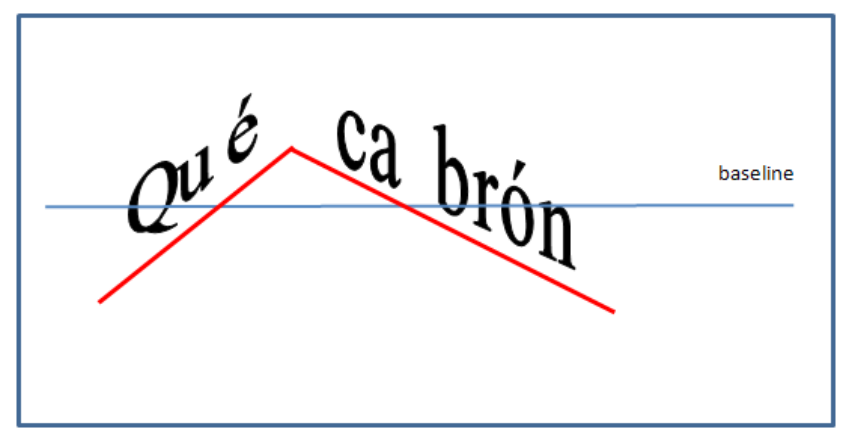

2.- Entonación irónica.

El segundo dialogo al que vamos a hacer referencia se desarrolla en el siguiente contexto: un chico del grupo hace referencia a su destreza para iniciar cierto contacto físico con una chica, destreza que despierta la envidia de los demás. En este contexto, no es difícil de entender que dicha destreza y el valor para llevarla a la práctica despierte la envidia sana de los demás, de modo que terminen viendo en su compañero a alguien digno de admiración y a su comportamiento como acto con un cierto grado de heroísmo. Dicho diálogo se desarrolla en los siguientes términos:

A: Pues Pedro no se ha cortado un pelo para coger a la rubia de la cintura...

B: ¡Joeh!, ya quisiera yo.

C: Ya ves, se levanta la mano, la miras a los ojos y al toro...

D: ¡Que cabrón!

En este caso, la exclamación iqué cabrón! se profiere con entonación ascendente. Hay un alargamiento de la "e" y menor énfasis en la sílaba final. El contenido de la expresión está ahora próximo al elogio o la admiración de quien posee una virtud que otros desearían poseer. En lo mostrado hasta ahora, la entonación constituye el signo diacrítico a partir del cual hay que entender la aprobación o desaprobación de lo acontecido y, consecuentemente, si se trata de un elogio o una reprobación hacia el sujeto de dichas acciones. 
Gráfico 2. Exclamación con tono ascendente. Sentido irónico

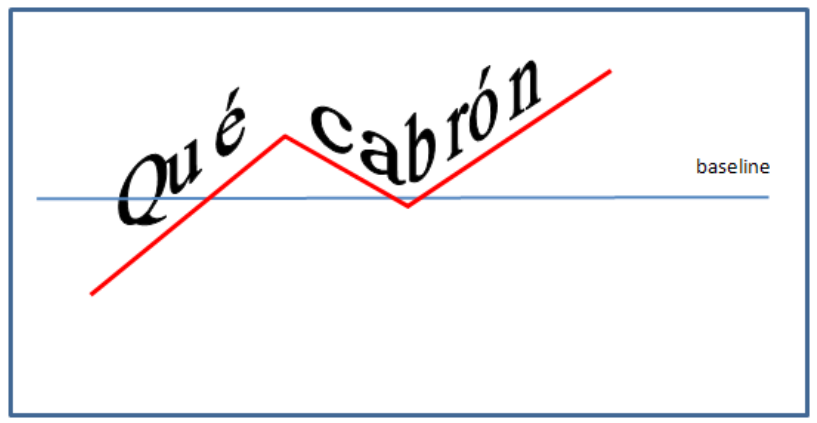

3.- Entonación plana u ondulada.

El tercer diálogo, que sigue a continuación, hemos de situarlo en el siguiente contexto: hay planeado un partido de fútbol entre el grupo de amigos. A mitad de partido, uno de los jugadores envía, sin querer, el balón al jardín de una casa próxima, a la que es imposible acceder al no estar los dueños en el domicilio. Ante la idea de dar el partido por concluido, uno de los participantes en el estudio trepa por el muro, salta al interior de la casa y recoge el balón, lo que les permite continuar jugando. Veamos el fragmento en cuestión:

A: Por poco nos quedamos sin partido

B: Y eso...

A: Pues porque Pablo no se ha enterado que esto no es el Bernabéu, y la pelota ha terminado en el jardín de esa casa.

C: Vaya futbolista está hecho el tronco...

D: ¿Y vive alguien ahí?

C: Pues ese es el problema...

D: Y entonces.

A: Pues nada, que Manolín ha hecho de las suyas: se ha saltado los cuatro metros de valla y ha recogido la pelota.

E: ¡Qué cabrón!

En este caso, la expresión ique cabrón! presenta una particularidad que la diferencia de las dos anteriores: se profiere con entonación neutra que se aproxima mucho a la línea media melódica. En este sentido, parece aproximarse a lo que Alcina y Blecua (1975) denominan ondulada. 
Gráfico 3. Exclamación con entonación plana

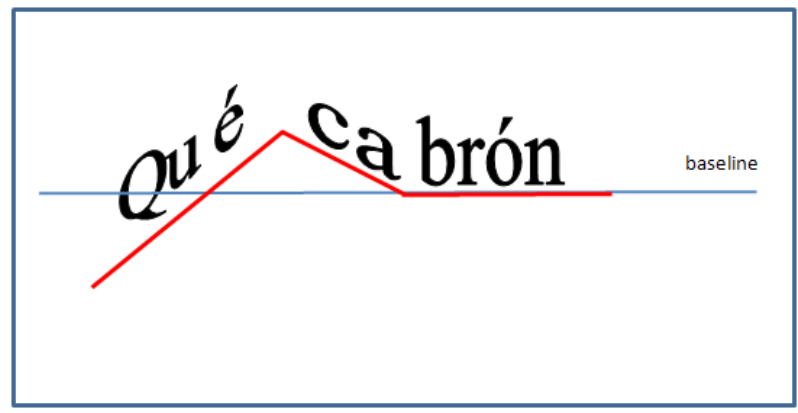

Como se observa, en los tres ejemplos aducidos se trata de exclamaciones de diverso tipo: ascendente, descendente o plana. Y parece ser esta entonación la que determina el contenido de cada expresión.

\section{ANÁlisis de los DATOS}

De acuerdo con la tradición lingüística, la citada exclamación no puede proferirse más que de dos formas: 1. De modo no irónico, es decir, mediante una entonación descendente. En tal caso, cabrón constituye un término ofensivo. En esta línea, el que profiere dicha expresión evidencia una posición ante lo acaecido, al manifestar su desacuerdo con lo realizado por el interlocutor y realizando una recriminación de carácter personal. 2 . Entonación irónica (ascendente). Dicha entonación es señal inequívoca de que hemos de interpretar la frase en sentido irónico. El significado, ahora, es el contrario al expuesto anteriormente. Ello significa que el hablante se posiciona favorablemente a la acción realizada, mostrando su aprobación o su adhesión.

Más problemático y mucho menos estudiado es el tercer caso. Lo que llama la atención es que el hablante no envía las señales necesarias para que el mensaje sea interpretado de una u otra de las formas referidas; es decir, evita, a nuestro entender, pronunciarse ante el hecho y dando libertad al oyente para que interprete la expresión en el sentido que le parezca más oportuno.

Así pues, creemos que estamos ante un caso de ambigüedad intencional, en la que el hablante prefiere no decantarse por ninguna de las dos opciones ya señaladas. El trasfondo de esta cuestión hay que buscarlo en la disonancia cognitiva. Dicha disonancia implica una falta de compatibilidad o de proporción entre la manera de sentir, de pensar, y la forma de actuar de una persona (Festinger 1957). Dicha disonancia puede surgir por múltiples causas: actuación contradictoria con opiniones expresadas, actuación en contra de una actitud concreta incluida en otra más general, etc. Para el citado autor, la tensión psicológica asociada a la disonancia se cuantifica en función de dos factores: la proporción 
entre cogniciones disonantes y cogniciones consonantes, y la importancia que cada persona otorga a cada una de estas cogniciones. En el ejemplo que nos ocupa, la persona que profiere el mensaje se halla ante la realización de un delito (allanar la propiedad privada, aunque sin mala intención y sin procurar ningún perjuicio), si bien se hace con la finalidad de continuar una actividad que el grupo desea realizar (el partido de fútbol). En consecuencia, el que profiere iqué cabrón! tiene que evaluar los dos hechos relevantes: por un lado, la comisión de un delito; por otro, el propiciar que se siga jugando el partido. Si da prioridad al primero, considerará a su compañero un delincuente, y habrá de entonar la expresión de modo no irónico. $\mathrm{Si}$, por el contrario, considera que el primer acto es irrelevante y prioriza la valentía de trepar un muro para permitir que se siga celebrando el partido, significa que percibe a su compañero como una persona digna de elogio, por lo que deberá proferir la expresión como ironía.

Como también señaló Festinger (1957), el grupo social en el que se inscribe un individuo es el origen de la disonancia cognitiva, a la vez que vehículo para reducir dichas disonancias. Las disonancias tienen lugar cuando una persona muestra discrepancia entre un determinado comportamiento y juicio o idea comúnmente aceptada. Tales ideas pueden estar basadas en consideraciones personales o sociales, así como en reglas y prescripciones de uso general en una determinada cultura (Stone y Cooper 2001 y 2003). Además, la homogenización de actitudes y el compartir usos y valores es un elemento de selección en la formación de grupos en la vida real (Moreland 1987). En este contexto algunas investigaciones se han centrado en el papel de la disonancia y la congruencia en relación con la percepción de la opinión pública (Eckhardt y Hendershot 1967). Estos autores establecen cuatro opciones fruto de la combinación de ámbitos: por un lado, la relación de nuestro comportamiento con nuestra percepción cognitiva, con dos opciones (consonante y disonante). Por otro, la relación entre el propio comportamiento y la opinión, normas y valores del grupo al que se está circunscrito, con otras dos opciones (congruente e incongruente). Probablemente, la persona que profiere iqué cabrón; enmascarando su contenido se halla en la tesitura de realizar un acto o expresión cuyo contenido es contrario a su percepción cognitiva; o bien, opuesto a las normas o valores que dan fundamento al grupo. Por ello, y para evitar ir contra las propias convicciones o contra las normas y valores que dan cohesión al grupo, se decanta por proferir un mensaje ambiguo. Ante la falta de señales claras para seleccionar uno u otro contenido, el oyente ha de desambiguar el mensaje llevándolo al significado que le parece más coherente.

\section{Conclusiones}

El presente trabajo ha puesto de relieve que uno de los mecanismos para crear ambigüedad intencional es el enmascaramiento de la ironía. Tal enmascaramiento es difícil de realizar más allá de aquellas fórmulas comúnmente reconocidas por los hablantes y posibles en su doble vertiente irónica/no irónica. En principio, la nómina de adjetivos 
capaces de conformar una estructura similar a la susodicha es pequeña: hijo(de)puta, y quizás con más reservas maricón. Cabe destacar también, en relación con lo que venimos observando, y así ha quedado constatado con el material recogido, que la expresión ique cabrón(a)! es proferida por personas de ambos sexos.

La neutralización de las entonaciones que aportan un contenido claro a la expresión parece responder a comportamientos ya estudiados por la Psicolingüística. Dicha neutralización está relacionada con la tensión que produce en el individuo el conflicto entre lo expresado y sus convicciones o entre lo expresado y las normas y valores que cohesionan el grupo del que forma parte. La citada neutralización intencional obliga al interlocutor a un ejercicio de desambiguación similar al que ocurre en ciertos chistes, metáforas, etc., en la que el hablante redefinirá el sentido de lo proferido en función de elementos como, por ejemplo, la congruencia que se supone a las reglas y normas que cohesionan el grupo. En esta proyección del comportamiento subjetivo sobre el lenguaje hay que tener en cuenta las características psicológicas del propio individuo (Matz y Wood 2005; Matz, Hofstedt y Wood 2008).

\section{Obras CITADas}

Albaladejo, Tomás. 1990. Retórica. Madrid: Síntesis. Alcina, Juan \& José M. Blecua. 1975. Gramática española. Barcelona: Ariel. Attardo, Salvatore. 2000a. "Irony Markers and Functions: Towards a Goal-Oriented Theory of Irony and its Processing". Rask 12: 3-20.

. "Irony as Relevant Inapropriateness". Journal of Pragmatics 32.6: 793-826.

Attardo, Salvatore, Jodi Eisterhold, Jennifer Hay \& Isabella Poggi. 2003. "Visual Markers of Irony and Sarcasm". Humor 16.2: 243-260.

Bach, Kent. 1998. “Ambiguity”. En Routledge Encyclopedia of Philosophy 1. London: Routledge.

Burgers, Christian, Margot Van Mulken \& Peter Jan Schellens. 2011. "Finding Irony: An Introduction of the Verbal Irony Procedure (VIP)". Metaphor and Symbol 26.3: 186205.

Casas, Raymundo. 2004. "Semántica y pragmática de la ironía verbal”. Letras 75.107-108: 117-141.

Clark, Eve. 1993. The Lexicon in Acquisition. Cambridge: Cambridge University Press.

Clark, Herbert \& Richard Gerrig. 1984. "On the Pretense Theory of Irony". Journal of Experimental Psychology 113.1: 121-126.

Colston, Herbert L. \& Sabrina Y. Lee. 2004. "Gender Differences in Verbal Irony Use". Metaphor and Symbol 19.4: 289-306.

Coseriu, Eugenio. 2007 [1980]. Lingüistica del texto. Introducción a la hermenéutica del sentido. Madrid: Arco /Libros.

Curcó, Carmen. 1998. "Indirect Echoes and Verbal Humour". En Villy Rouchota y Andreas Jucker, Eds., Current Issues in Relevance Theory. Amsterdam: John Benjamins. 305-326. 
Dews, Shelly, Joan Kaplan \& Ellen Winner. 1995. "Why not Say it Directly? The Social Function of Irony”. Discourse Processes 19: 347-368.

Dews, Shelly \& Ellen Winner. 1997. "Attributing Meaning to Deliberately False Utterances". En Charlotte Mandell y Allyssa McCabe, Eds., The Problem of Meaning: Behavioral and Cognitive Perspectives. Amsterdam: Elsevier Press. 377-414.

Dress, Megan, Roger J. Kreuz, Kristen E. Link \& Gina M. Caucci. 2008. "Regional variation in the use of sarcasm". Journal of Language and Social Psychology 27.1: 71-85.

Eckhardt, Kenneth W. \& Gerry Hendershot. 1967. "Dissonance-Congruence and the Perception of Public Opinion". The American Journal of Sociology 73.2: 226-234.

Festinger, Leon. 1957. A Theory of Cognitive Dissonance. California: Stanford University Press.

Gibbs, Raymond W. 1994. The Poetics of Mind: Figurative Thought, Language, and Understanding. Cambridge: Cambridge University Press. 2000. "Irony in Talk among Friends". Metaphor and Symbol 15: 5-27. 2012. "Are Ironic Acts Deliberate?". Journal of Pragmatics 44: 104-115.

Gibbs, Raymond W. \& Herbert Colston (eds.). 2007. Irony in Language and Thought: A Cognitive Science Reader. Philadelphia: Taylor and Francis.

Gibbs, Raymond W. \& Christin D. Izett. 2005. "Irony as persuasive communication". En Herbert L. Colston y Albert N. Katz, Eds., Figurative Language Comprehension: Social and Cultural Influences. Mahwah: Lawrence Elbaum. 131-151.

Giora, Rachel. 1995. “On Irony and Negation”. Discourse Processes 19.2: 239-264. . 1997. "Discourse Coherence and Theory of Relevance: Stumbling Blocks in Search of a Unified Theory". Journal of Pragmatics 27: 17-34.

Goddard, Cliff. 2006. "Lift your Game Martina!”: Deadpan Jocular Irony and the Ethnopragmatics of Australian English”. En Cliff Goddard, Ed., Ethnopragmatics: Understanding Discourse in Cultural Context. Berlin: Mouton de Gruyter. 65-97.

Grice, Herbert P. 1975. "Logic and Conversation." En Peter Cole and Jerry L. Morgan, Eds., Syntax and Semantics, vol. 3: Speech Acts. New York: Academic Press. 41-58.

Katz, Albert. N. \& Penny M. Pexman. 1997. "Interpreting Figurative Statements: Speaker Occupation Can Change Metaphor to Irony”. Metaphor and Symbol 12.1: 19-41.

Kaufer, David. 1977. "Irony and Rhetorical Strategy". Philosophy and Rhetoric 10: 90-110.

Kerbrat-Orecchioni, Catherine. 1980. "L' ironie comme trope". Poètique 41: 108-127.

Kittay, Eva. F. 1987. Metaphor: Its Cognitive Force and Linguistic Structure. Oxford: Clarendon.

Kocman, Ana. 2011. La ironía verbal como semejanza incongruente. Tesis doctoral. Universidad de Salamanca, España.

Kreuz, Roger. J. 1996. “The Use of Verbal Irony: Cues and Constraints”. En Jeff Mio and Albert N. Katz, Eds., Metaphor: Implications and Applications. Mahwah: Erlbaum. 23-38.

Lehrer, Adrienne. 1990. "Polisemy, Conventionality and the Structure of the Lexicon". Cognitive Linguistics 1: 207-246. 
Lucariello, Joan. 1994. "Situational Irony: A Concept of Events Gone Awry". Journal of Experimental Psychology 123: 129-145.

Machado, Ida. 2014. "A ironia como estratégia comunicativa e argumentativa". Bakhtiniana: Revista de Estudos do Discurso 9.1: 26-36.

Matz, David C. \& Wendy Wood. 2005. "Cognitive Dissonance in Groups: The Consequences of Disagreement". Journal of Personality and Social Psychology 88: 22-37.

Matz, David. C., Petra M. Hofstedt \& Wendy Wood. 2008. "Extraversion as a Moderator of the Cognitive Dissonance Associated with Disagreement". Personality and Individual Differences 45: 401-405.

Mey, Jacob L. 1993. Pragmatics. An Introduction. Oxford: Blackwell.

Michelena, L. 1972. "De la ambigüedad sintáctica”. Revista Española de Lingüistica 2: 237 248.

Moreland, Richard L. 1987. "The Formation of Small Groups". En Clyde Hendrick, Ed., Group processes: Review of Personality and Social Psychology 8. Newbury: Sage. 80-110.

Moreno, Juan C. 1994. Curso universitario de lingüística general. Madrid: Síntesis.

Nerlich, Brigitte \& David Clarke. 2001. "Ambiguities We Live by: Towards a Pragmatics of Polysemy”. Journal of Pragmatics 33: 1-20.

Partington, Alan. 2007. "Irony and Reversal of Evaluation". Journal of Pragmatics 39.9: 1547-1569.

Roberts, Richard M. \& Roger J. Kreuz. 1994. “Why Do People Use Figurative Language?”. Psychological Science 5: 159-163.

Shamay-Tsoory, Simone G., Rachel Tomer \& Judith Aharon-Peretz. 2005. "The Neuroanatomical Basis of Understanding Sarcasm and Its Relationship to Social Cognition". Neuropsychology 19.3: 288-300.

Shelley, Cameron. 2001. "A Bicoherence Theory of Situational Irony". Cognitive Science 25.5: $775-818$.

Stone, Jeff \& Joel Cooper. 2001. "A Self-standard Model of Cognitive Dissonance". Journal of Experimental Social Psychology 37: 228-243. . 2003. "The Effect of Self-attribute Relevance on How Self-esteem Moderate Dissonance Processes". Journal of Experimental Social Psychology 39: 508-515.

Wilson, Deidre \& Dan Sperber. 1992. “On Verbal Irony”. Lingua 87.1: 53-76. 